\title{
DOIS ANOS DE ANTROPOLOGIA FORENSE NO CENTRO DE MEDICINA LEGAL (CEMEL) DA FACULDADE DE MEDICINA DE RIBEIRÃO PRETO-USP
}

\author{
TWO YEARS OFFORENSIC ANTHROPOLOGY ATTHE MEDICO LEGALCENTRE(CEMEL) \\ OFTHE FACULTY OF MEDICINE OF RIBEIRÃO PRETO-USP
}

Andjara T. C. Soares ${ }^{1}$, Marco A. Guimarães ${ }^{2}$

${ }^{1}$ Pós-graduanda. ${ }^{2}$ Docente. Departamento de Patologia da Faculdade de Medicina de Ribeirão Preto - USP. Centro de Medicina Legal (CEMEL).

CorResPondência: Prof. Dr. Marco Aurélio Guimarães. Departamento de Patologia da Faculdade de Medicina de Ribeirão Preto - USP. CEMEL. Rua Tenente Catão Roxo no 2418, Ribeirão Preto, São Paulo, 14051-140, Brasil.

Tel.: +55-16-36023358; fax: +55-16-36334476. E-mail: mag@fmrp.usp.br

Soares ATC, Guimarães MA. Dois anos de Antropologia Forense no Centro de Medicina Legal (CEMEL) da Faculdade de Medicina de Ribeirão Preto-USP. Medicina (Ribeirão Preto) 2008; 41 (1): 7-11.

RESUMO: A Antropologia Forense é uma área do conhecimento que busca estabelecer a identidade de um sujeito através da individualização de características intrínsecas a ele. O Centro de Medicina Legal (CEMEL) da Faculdade de Medicina de Ribeirão Preto da Universidade de São Paulo (FMRP-USP) possui um Laboratório de Antropologia Forense, criado em parceria com a University of Sheffield (UK), que elaborou um protocolo para análise de ossadas e esforça-se para desenvolver um trabalho mais confiável, que permita resultados sociais e científicos de alta qualidade. Após dois anos de funcionamento, constatou-se que muitas das ossadas encaminhadas ao CEMEL não possuem elementos que são de extrema importância para a realização do exame antropológico, o que pode evitar a elaboração de um perfil biológico adequado da ossada e, em virtude disso, postergar a sua identificação. Considerando-se que não há dados antropológicos recentes na literatura nacional sobre casos médico-legais de ossadas, este é o primeiro trabalho realizado a partir da análise de 42 ossadas humanas encaminhadas ao CEMEL desde sua inauguração em 1999. Os resultados mostraram como principais características antropológicas das ossadas estas estarem relacionadas a indivíduos masculinos, de origem étnica caucasiana, com idade entre 32,71 e 46,29 anos, estatura entre 1,64 e 1,73m, destros, sem achados patológicos relevantes, com elementos odontológicos informativos e sem roupas ou outros pertences. Além disso, foi constatado que $61,90 \%$ das ossadas possuíam menos de $50 \%$ dos ossos, com média de $79,64 \pm 52,40$ ossos por caso. Diante disso, discute-se a necessidade de melhorias na capacitação técnica e de condições de trabalho para os responsáveis pela coleta de ossadas no seu local de encontro, assim como no seu transporte, de forma a aumentar o número de ossos coletados e, como conseqüência, de informações para possíveis identificações.

Descritores: Medicina Legal. Antropologia Forense. Esqueleto. Ossos.

\section{1- INTRODUÇÃO}

A Medicina Legal, segundo Hoffman (apud Hércules"), "é a ciência que tem por objeto o estu- do das questões no exercício da jurisprudência civil e criminal e cuja solução depende de certos conhecimentos médicos prévios". É, portanto, uma ciência de largas proporções e de extraordinária im- 
portância no conjunto dos interesses da coletividade, uma vez que ela existe e se exercita cada vez mais em razão das necessidades da ordem pública e do equilíbrio social ${ }^{2}$.

Apesar de suas várias denominações, como medicina forense e ciências forenses, o termo Medicina Legal é o mais utilizado no Brasil, sendo consagrado pelo seu uso.

No Brasil, a Medicina Legal possui muitas deficiências como conseqüência de uma série de problemas históricos. Nosso país possui um agitado passado histórico político. O Brasil foi uma colônia portuguesa e teve sua população formada por sul americanos nativos e escravos africanos dominados pelos europeus. Após a independência, tornou-se uma monarquia e, depois, esteve sob controle militar no século 19. Durante o século 20 ocorreu uma sucessão de presidentes civis, dos quais um deles foi considerado ditador. Apenas recentemente a democracia foi reimplantada. Durante os anos ditatoriais, a Medicina Legal esteve sob estrito controle e foi seriamente afetada, principalmente nas áreas de antropologia e identificação humana, pois muitas vezes não era de interesse a determinação da identidade de desaparecidos por razões políticas. Por causa desse controle, o ensino e a pesquisa na área também foram grandemente afetados por um longo tempo ${ }^{3}$.

A primeira tentativa de gerar alguma modificação na estrutura médico-legal no Brasil ocorreu com a idealização do Centro de Medicina Legal (CEMEL) da Faculdade de Medicina de Ribeirão Preto da Universidade de São Paulo (FMRP/USP). O CEMEL foi criado a partir de um acordo entre o Núcleo de Perícias Médico-Legais (NPML) de Ribeirão Preto - subordinado à Secretaria de Segurança Pública do Estado de São Paulo (SSP-SP) - e à FMRP/USP através do Departamento de Patologia, responsável pelo ensino de Medicina Legal na FMRP. Tal acordo, firmado em 1996 (Proc. CS5389-91 DOE Seção I - 106 (122) 28/6/96), prevê a "cooperação técnico-científica mútua nas áreas de perícia e pesquisa no campo da Medicina Legal, objetivando a celeridade e o aperfeiçoamento das investigações criminais".

OCEMEL veio solucionar o problema da falta de ensino prático de Medicina Legal na FMRP, pois esta, assim como grande parte das escolas médicas do Brasil, não dispunha do material vindo das perícias médico-legais, visto que tais perícias, devido à lei, são de responsabilidade exclusiva do Instituto Médico-legal (IML). Além disso, esse Centro possibilita ao IML acesso à infra-estrutura científica da Universidade, assim como seus qualificados recursos humanos, o que melhora a qualidade dos serviços prestados à sociedade.

O CEMEL possui hoje serviços de Tanatologia Forense, Toxicologia Forense, Perícias e, recentemente, um setor de Antropologia Forense que foi criado mediante um acordo entre a FMRP/USP e a University of Sheffield (UK) através do projeto "UK - Brazil Scientific Cooperation - Forensic Anthropology and Identification of Human Remains", financiado pelo Global Opportunities Fund do Governo Britânico, visando buscar a identificação de ossadas através de um protocolo para análise de ossadas adequado à realidade local e a criação de um banco de dados com os achados antropológicos.

A Antropologia Forense é uma especialidade relativamente recente que aplica os métodos da antropologia física e arqueologia para coleta e análise de evidências legais, buscando estabelecer a identidade do sujeito através da individualização de características intrínsecas àquela situação $0^{4,5}$. Esta área do conhecimento iniciou-se no século 20 e vem sendo incrementada devido ao exponencial aumento da violência, pela necessidade do conhecimento da anatomia do esqueleto em ações jurídicas que envolvam a identificação e avaliação de restos humanos em decomposição ou esqueletizados ${ }^{5}$.

Segundo James \& Nordby ${ }^{6}$, o exame de restos humanos por antropologistas forenses deve ser focado em três tarefas: I) identificar a vítima ou pelo menos providenciar um perfil biológico, incluindo sexo, idade, estatura, ancestralidade, destreza manual, anomalias, patologias e características individuais; II) reconstruir o período post-mortem baseado nas condições dos restos e a recuperação do contexto e III) fornecer dados sobre o evento da morte, incluindo evidência de trauma ocorrendo no período peri-mortem. É necessária uma equipe multidisciplinar (médicos, biólogos, cirurgiões dentistas, entre outros) para realizar essas tarefas e, a partir delas, desenvolver um perfil biológico completo do indivíduo de tal maneira que se possa estreitar a variedade das possíveis identidades.

No Brasil, existe uma carência de dados de Antropologia Forense e, em virtude disso, quando uma análise é realizada torna-se necessário utilizar dados comparativos gerados em populações americanas, européias ou asiáticas com pouca miscigenação ou com miscigenação distinta da brasileira, o que pode produzir dados incorretos e impedir ou dificultar a identificação médico-legal.

A literatura nacional não possui informações sobre dados antropológicos sobre quais elementos são 
freqüentemente encaminhados juntamente com as ossadas (além de ossos, roupas, pertences, entre outros). Diante disso, foi realizada uma análise detalhada desses elementos para organização de um trabalho em Antropologia Forense mais confiável, que permitirá no futuro um resultado social e científico de maior qualidade.

\section{2- MATERIAL E MÉTODOS}

\section{1- Aspectos éticos}

O trabalho foi analisado e aprovado pelo Comitê de Ética em pesquisa do Hospital das Clínicas da FMRP/USP, processo HCRP n ${ }^{\circ} 14984 / 2005$. O trabalho contou com a autorização do Centro de Exames, Análises e Pesquisas (CEAP) e do NPML de Ribeirão Preto.

\section{2- Análise das ossadas}

Para realizar a análise de uma ossada primeiramente é necessário que a mesma esteja limpa, em condições de ser avaliada. Às vezes é necessário realizar a redução do cadáver (processo de eliminação de restos de tecidos moles aderidos aos ossos), devido à presença de restos ainda em decomposição que impossibilitam a sua identificação. Entretanto, a maioria dos casos dá entrada no CEMEL em esqueletização completa ou com poucos restos de tecidos dessecados que não interferiram na análise.

Em seguida, a ossada deve ser distribuída em posição anatômica em mesa apropriada. É importante observar sempre a lateralidade dos ossos (direito ou esquerdo), assim como a sua correta localização, principalmente de costelas e vértebras. Após esta etapa, o Relatório de Exame de Antropologia Forense (REAF) é realizado, apresentando dados sobre o inventário completo e detalhado de todos os ossos presentes, fotos do esqueleto em posição anatômica e de achados patológicos eventuais. Um inventário detalhado da dentição também é realizado, com inserção de fotos da dentição superior e inferior. Em seguida, faz-se uma descrição detalhada das vestes e de outros itens, associando-se as respectivas fotos, de forma a permitir que seja realizado o reconhecimento futuro de alguma peça de roupa, o que pode ser utilizado como triagem para uma possível identificação.

Uma vez concluído o inventário completo do esqueleto, evolui-se para a análise de características antropológicas na seguinte sequiência: avaliação do sexo através da pelve; avaliação do sexo pelo crânio; avaliação de ancestralidade (crânio e outros elementos); estimativa de idade em adultos (clavícula, sínfise púbica, articulação sacro-ilíaca, quarta costela, coluna vertebral) ou em jovens (fechamento de cartilagens epifisárias dos ossos); estimativa de estatura (medidas de ossos longos); estimativa da destreza manual; análise de características odontológicas. As informações para realização dessas análises foram obtidas da literatura especializada ${ }^{4,6 / 11}$.

Ao final, um resumo com os dados principais de cada caso é elaborado de forma a facilitar a organização dos dados e sua posterior análise comparativa para fins de identificação.

\section{3- Análise dos dados}

Todas as informações das ossadas presentes nos REAF foram organizadas e tabuladas de maneira a permitir a análise quantitativa dos dados através de estatística descritiva simples.

\section{3- RESULTADOS E DISCUSSÃO}

Até o ano de 2006 foram encaminhadas ao CEMEL 44 ossadas. Todas foram analisadas e um REAF foi elaborado para cada um.

Dos 44 casos, dois eram de ossos não-humanos. Portanto, foram analisadas 42 ossadas humanas. Destas, verificou-se a média de $79,64 \pm 52,40$ ossos por caso.

De acordo com o REAF, que contém a descrição nominal de todos os ossos, um esqueleto completo possui 201 ossos. Vinte e um casos (50\%) possuem 76 ossos ou menos, o que corresponde a $37,81 \%$ do total de ossos. Apenas 16 casos possuem mais de 50\% dos ossos (acima de 101 ossos), o que corresponde a $38,10 \%$ dos laudos produzidos. Em contrapartida, os demais 26 laudos $(61,90 \%)$ possuem menos de $50 \%$ do total de ossos do esqueleto.

Partindo-se do fato de que todas as informações a respeito de uma ossada são obtidas através dos ossos, quanto maior a quantidade de ossos encaminhados em cada ossada, maior a quantidade, e possivelmente a qualidade, dos dados que podem ser obtidos a partir da mesma. Portanto, para que se realize uma análise de maior confiança é necessário que a ossada esteja o mais completa possível, o que destoa da situação descrita acima em que geralmente as mesmas estão incompletas. 
Frente ao acima descrito, torna-se necessário estudar soluções para aumentar o número de ossos recolhidos por caso de ossada encontrada. Mesmo considerando as particularidades específicas de cada situação de encontro de ossada, torna-se premente a necessidade da melhoria da capacitação dos profissionais responsáveis pelo recolhimento dos ossos encontrados através de cursos específicos em técnicas antropológicas. Pequenos ossos podem ser confundidos com pedras no seu recolhimento, estarem espalhados pela ação de animais carniceiros ou ainda ocasionalmente serem perdidos durante o transporte, considerando-se o modo como estes procedimentos são executados atualmente. Cabe salientar que este trabalho não é executado pelos profissionais que farão a análise posterior dos ossos.

Todos os laudos dos casos de ossadas encaminhadas ao CEMEL foram analisados com a finalidade de reunir os dados para determinar as características antropológicas mais comuns observadas.

A análise do sexo permitia avaliar se a ossada era do sexo masculino, feminino ou, caso isso não fosse possível, classificá-la como de sexo não-determinado, quando na ausência de elementos para análise. Das 42 ossadas analisadas, 38 (90,48\%) são do sexo masculino, apenas duas $(4,76 \%)$ do sexo feminino e em duas ossadas $(4,76 \%)$ não foi possível determinar o sexo.

Em relação à ancestralidade, uma ossada pode ser classificada como pertencente a indivíduo caucasiano, africano, mestiço ou não-determinado, quando os elementos presentes não permitem que a análise seja realizada. Do total analisado, 18 ossadas $(42,86 \%)$ apresentam ancestralidade caucasiana, quatro $(9,52 \%)$ possuem ancestralidade africana, $10(23,81 \%)$ são de ancestralidade mista (mestiça) e em $10(23,81 \%)$ não foi possível determinar a ancestralidade.

A análise da idade forneceu um intervalo de idades (mínima, média e máxima) ou uma idade mínima. A curva referente à idade mínima apresenta pico máximo na idade de 35 até 40 anos (10 casos); a de idade média possui pico na idade de 40 a 45 anos (sete casos) e a de idade máxima apresenta pico na idade de 55 a 60 anos (10 casos). Além disso, a média de cada grupo de dados (idades mínima e máxima) também foi analisada. Dessa forma, pode-se verificar que o intervalo médio de idades é de 32,71 a 46,29 anos.

Procedimento similar foi aplicado para a análise de estatura. A curva para a estatura mínima apresenta pico entre 1,60 e 1,61m (cinco casos). Para a estatura média, os picos estão de 1,64 a $1,65 \mathrm{~m}$; de
1,68 a $1,69 \mathrm{~m}$ e de 1,72 a $1,73 \mathrm{~m}$, cada um deles com quatro casos. A estatura máxima apresenta picos de 1,68 a $1,69 \mathrm{~m}$; de 1,72 a $1,73 \mathrm{~m}$ e de 1,76 a $1,77 \mathrm{~m}$, também com quatro casos em cada. A média de cada grupo de dados (estatura mínima e máxima) também foi calculada, sendo o intervalo médio de estaturas de 1,64 a $1,73 \mathrm{~m}$.

Outro dado obtido através da análise antropológica foi a destreza manual, ou seja, a predominância do uso da mão direita ou esquerda Em alguns casos a destreza não pode ser determinada. Das ossadas analisadas, $15(35,71 \%)$ apresentaram sinais de predominância do uso da mão direita (destros), apenas três $(7,14 \%)$ para uso da mão esquerda (sinistros ou "canhotos") e em 24 casos $(57,14 \%)$ não foi possível determinar a destreza manual, na maioria dos casos por ausência de elementos ósseos que viabilizassem a análise.

A presença de achados patológicos nos ossos também foi outra característica analisada, sendo possível classificar a presença, ausência ou a dúvida, nos casos, por exemplo, de dificuldade de afirmação sobre a ocorrência ante, peri ou post-mortem de uma fratura. Em 17 casos $(40,48 \%)$ foram encontrados achados patológicos, em 24 casos $(57,14 \%)$ não estavam presentes achados patológicos e em apenas um caso $(2,38 \%)$ ocorreu dúvida na determinação da presença ou ausência de achado patológico.

Informações sobre os dentes também foram obtidas na análise antropológica, pois a comparação com registros em vida pode desencadear a identificação. Das 42 ossadas analisadas, 33 (78,57\%) apresentam informações sobre os dentes e nove casos $(21,43 \%)$ não possuíam dentes para análise.

Dos 42 casos presentes no CEMEL, 19 foram encaminhados juntamente com roupas e outros pertences, o que corresponde a $45,24 \%$ do total. Em contrapartida, $23(54,76 \%)$ ossadas não possuíam nenhum pertence.

Portanto, reunindo todos os dados, podemos afirmar que as características antropológicas mais comuns observadas nas ossadas encaminhadas ao CEMEL são relativas a indivíduos do sexo masculino (40 ossadas $=$ $90,48 \%$ ), caucasianos (18 ossadas $=42,86 \%)$, com idade entre 32,71 e 46,29 anos, estatura entre 1,64 e $1,73 \mathrm{~m}$ e destros $(15$ ossadas $=35,71 \%)$ ou com destreza manual não determinada $(24$ casos $=57,14 \%)$. Além disso, predomina a ausência de achados patológicos ( 24 ossadas $=57,14 \%)$, a presença de informações dentárias (33 casos $=78,57 \%$ ) e a ausência de roupas e outros pertences ( 23 ossadas $=54,76 \%$ ). 


\section{4- CONCLUSÕES}

1. As ossadas encaminhadas ao CEMEL/FMRPUSP são, em sua maioria, incompletas, com menos de $50 \%$ do total de ossos.

2. São necessárias melhorias no treinamento específico dos responsáveis pela coleta de ossadas, de forma a aumentar o número de ossos coletados e melhorar a qualidade do exame antropológico.

3. As características predominantes das ossadas encaminhadas ao CEMEL são: indivíduos do sexo masculino, caucasianos, com idade entre 32,71 e
46,29 anos, estatura entre 1,64 e 1,73m, destros ou sem destreza manual definida, sem achados patológicos, com elementos dentários para análise e sem roupas e outros pertences.

\section{5- AGRADECIMENTOS}

À CAPES, pela bolsa de pós-graduação. Ao Global Opportunities Fund do Governo Britânico, pelo apoio financeiro à criação do Laboratório de Antropologia Forense. À Teresa Cristina Pantozzi Silveira e José Marcelo Schieri pelo auxílio técnico na preparação das ossadas.

Soares ATC, Guimarães MA. Two years of Forensic Anthropology at the Medico Legal Centre (CEMEL) of the Faculty of Medicine of Ribeirão Preto-USP. Medicina (Ribeirão Preto) 2008; 41 (1): 7-11.

ABSTRACT: Forensic Anthropology is an area of knowledge which works in the establishment of a person's identity through the individualization of his or her intrinsic characteristics. The Medico Legal Centre (CEMEL) of the Faculty of Medicine of Ribeirão Preto of University of São Paulo (FMRP-USP) has a Laboratory of Forensic Anthropology, which was created in a partnership with the University of Sheffield (UK), which elaborated a protocol for skeletons analysis and put efforts to develop a more reliable work to allow high quality social and scientific results. After two years of work, it was noticed that many skeletons forwarded to CEMEL did not have extremely important elements for the anthropological examination, which could avoid the elaboration of an adequate biological profile of the skeletons and, because of this, postpone its identification. Considering that there is no recent anthropological data in national literature about medico-legal cases of skeletons, this is the first report about the analysis of 42 human skeletons forwarded to CEMEL since its inauguration in 1999. The results showed the main anthropological characteristics of the skeletons as being related to male individuals, from Caucasian ethnic origin, age between 32.71 and 46.29 y.o., height between 1.64 and 1.73, dexterous, without any relevant pathological findings, with informative odontological elements and no clothes or other belongings. Besides, it was evidenced that $61.90 \%$ of the skeletons had less than $50 \%$ of the bones, with mean of $79.64 \pm 52.40$ bones per case. Considering this, it is discussed the necessity of improvements in technical qualification and working conditions for those responsible for skeletons collection in the place they are found, as well as their transport, in a way to increase the number of collected bones and, as a consequence, of information for possible identifications.

Keywords: Forensic Medicine. Forensic Anthropology. Skeleton. Bones.

\section{REFERÊNCIAS}

1 - Hoffman apud Hercules HC. Medicina Legal. São Paulo: Atheneu; 2005, p. 10.

2 - França GV. Medicina Legal. 7ª edição. Rio de Janeiro: Guanabara Koogan; 2004.

3 - Guimarães MA. The challenge of identifying deceased individuals in Brazil: from dictatorship to DNA analysis. Sci Justice 2003; 43 (4): 215-7.

4 - Burns KR. Forensic anthropology training manual. Upper Saddle River (New Jersey): Prentice Hall; 1999.

5 - Hercules HC. Medicina Legal. São Paulo: Atheneu; 2005.

6 - James SH, Nordby JJ. Forensic science: an introduction to scientific and investigative techniques. Boca Raton: CRC Press; 2003.
7 - Bass WM. Human osteology: a laboratory and field manual. 4th ed. Columbia: Missouri Archaeological Society; 1995.

8 - Reichs KJ. Forensic osteology: advances in the identification of human remains. 2nd ed. Springfield: Charles C Thomas Publisher; 1998.

9 - White TD, Folkens PA. Human osteology. 2nd ed. San Diego: Academic Press; 2000.

10 - Ortner DJ. Identification of pathological conditions in human skeletal remains. 2nd ed. San Diego: Academic Press; 2003.

11 - White TD, Folkens PA. The human bone manual. San Diego: Elsevier Academic Press; 2005.

Recebido para publicação em 27/08/2007

Aprovado para publicação em 13/05/2008 